\title{
Shaping ability of Mtwo and Twisted File rotary systems in curved root canals
}

\author{
David Uroz-Torres ${ }^{1}$, María Paloma González-Rodríguez ${ }^{2}$, Carmen María Ferrer-Luque ${ }^{3}$ \\ ${ }^{1}$ DDS, PhD. Private Practice. Department of Stomatology, School of Dentistry. University of Granada (Spain). \\ ${ }^{2}$ DDS, PhD. Associate Professor. Department of Stomatology, School of Dentistry. University of Granada (Spain). \\ ${ }^{3}$ DDS, MD, PhD. Associate Professor. Department of Stomatology, School of Dentistry. University of Granada (Spain).
}

Correspondence:

Department of Stomatology, School of Dentistry

Campus de Cartuja, Colegio Máximo s/n.

E-18071, Granada (Spain)

E-mail address: cferrer@ugr.es

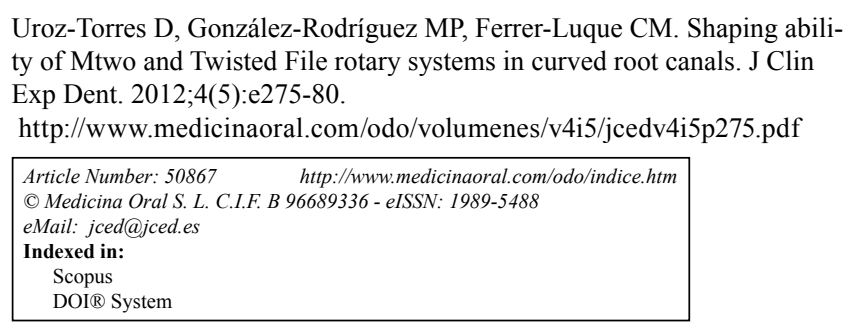

\begin{abstract}
Objective: To compare the straightening of root canal curvature, the apical transportation, the loss of working length and the working time using two rotary systems.

Study design: Sixty buccal root canals with angles of curvature between 30 to $99^{\circ}$ were instrumented with Mtwo and Twisted File rotary instruments. A series of pre- and post-operative radiographs were superimposed to determine the straightening of root canal curvature and apical transportation. The loss of working length and working time were also calculated.

Results: All data were analyzed by means of the Student's $t$-test and Mann-Whitney $U$-test. No statistically significant differences in the straightening of root canal curvature, apical transportation, or the loss of working length were found between groups. There was a significant difference in working time between angles of curvature when using the Mtwo system.

Conclusion: Both rotary systems showed minimal changes in the original root canal curvature.
\end{abstract}

Key word: apical transportation; curved root canals; Mtwo system; root canal preparation; Twisted File system. 


\section{Introduction}

During cleaning and shaping of curved root canals, several procedural errors can occur. Such iatrogenic accidents include apical transportation, zips, ledges, root perforations, loss of working length or straightening of root canals (1). When a curved root canal is enlarged, the use of progressively greater files decreases the angle of curvature, owing to the tendency to move towards the outer wall of the root canal (2), for which reason a noninstrumented inner dentine wall in the apical third may entail a worse prognosis for treatment (3).

Nickel Titanium (NiTi) alloy has a lower modulus of elasticity than stainless steel (4). This property allows NiTi files to be placed in curved root canals with less lateral force exerted against the root canal walls (5). Yet along with this advantage, NiTi also has a straightening tendency, especially in instruments with greater taper and tip. File designs, rotational speed, different sequences of instrumentation, surface conditioning of the instruments and clinician's experience are important factors for efficient instrumentation (6). The influence of file designs on apical transportation or shaping ability has been widely investigated $(7,8,9)$. It was recently shown that the cross-sectional design has a greater impact than the taper or size of an instrument on the stresses developed therein under either torsion or bending (10).

The files of the Mtwo (M2) system (VDW, Munich, Germany) feature an S-shaped cross-sectional design, a positive rake angle with two cutting edges, and increasing pitch length from the tip to the shaft. When comparing with other rotary systems has shown more shaping ability and cleaning efficiency in curved root canals $(8$, 9), with capacity for penetration and cutting superior to Alpha-File (Komet, Lemgo, Germany), FlexMaster (VDW, Munich, Germany) and ProFile (Dentsply Maillefer, Ballaigues, Switzerland) (11). In addition, Mtwo has been shown highest cyclic fatigue resistance, in apical abrupt curvatures, when compared with ProTaper Universal (Dentsply Maillefer, Ballaigues, Switzerland),
FlexMaster and ProFile instruments (12) and higher corrosion resistance than RaCe files (FKG, La Chaux-deFonds, Switzerland) (13).

The files of the Twisted File (TF) system (SybronEndo Orange, CA) have a triangular cross section with constant tapers $(.04, .06, .08, .10$, and .12) available in 5 tip sizes (25-50). The manufacturing characteristics such as R-phase heat treatment, twisting the metal, and special surface conditioning are marketed to produce a more flexible NiTi rotary instrument (14). There are recent reports of TF instruments that produced significantly less transportation and remained more centered inside the root canal than PathFile-ProTaper and conventional stainless steel K-files in root canals with severe curvature (15). To the best of our knowledge, no other studies have focused on the single length technique using M2 in comparison with TF crown-down technique.

The aim of this study was to compare the straightening of root canal curvature, apical transportation, loss of working length and the working time with $\mathrm{M} 2$ and TF instruments in root canals with $30-99^{\circ}$ curvature angles.

\section{Material and methods \\ Specimen Preparation}

Sixty mandibular molars extracted for periodontal reasons were stored in a $2 \%$ thymol solution until use. The crown of each tooth was removed at the level of the cementum enamel junction using a diamond disc in an Accutom 50 cutting machine (Struers, Ballerup, Denmark) to obtain a mesio-buccal root canal measuring $12 \mathrm{~mm}$ in length. The working length was determined by subtracting $1 \mathrm{~mm}$ from the length at which the file tip extruded apically. The specimens were embebed in acrilic resin (Implex ${ }^{\mathrm{TM}}$, Italy) employing an endodontic cube (16). A \#08 stainless steel K-type hand file (Dentsply/Maillefer, Ballaigues, Switzerland) was situated at working length (WL) and digital radiographs were taken for each specimen. Adobe Photoshop CS4 software (Adobe Systems Inc., San Jose, CA) was used to enhance the edges
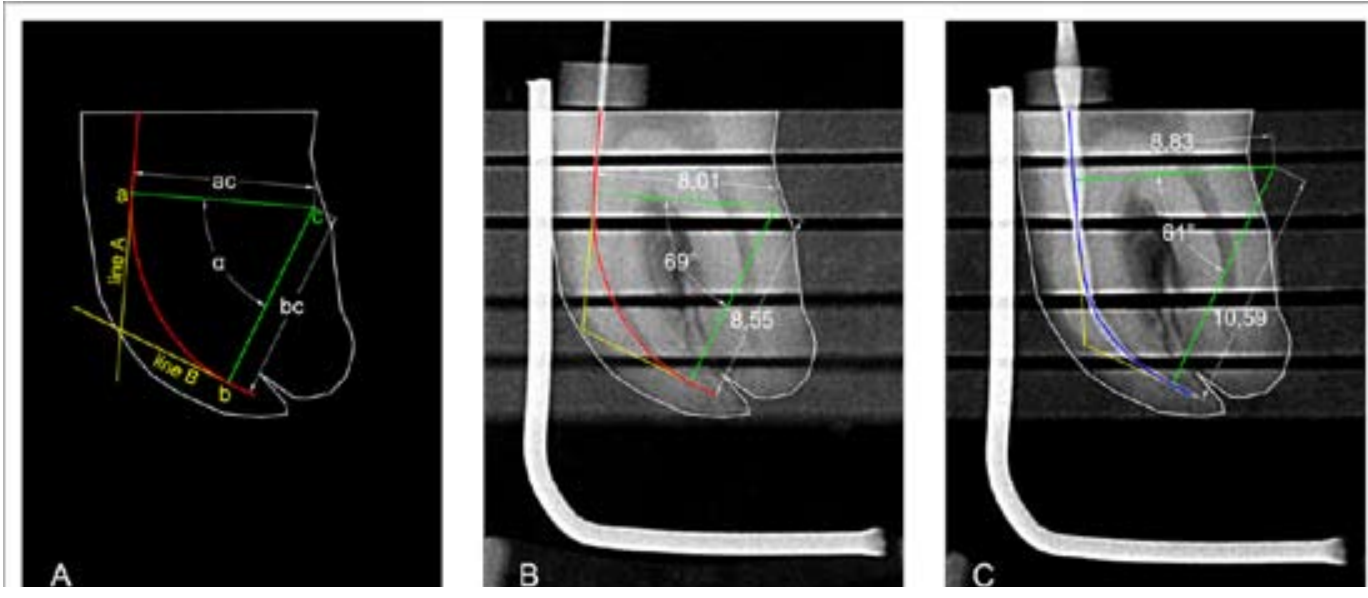

Fig. 1. Representative images of Pruett's method. A. Diagram; B. Pruett's method applied to radiograph pre-instrumentation; C. Pruett's method applied to radiograph post-instrumentation. 
of the initial and final instrumentation radiographs.

The angle and radius of the root canal curvature were determined according to the methodology of Pruett et al. (17) (Fig. 1) using the computerized digital image processing system AutoCAD 2008 (Autodesk Inc., San Rafael, CA). The roots whose angles of curvature ranged between 30 and $99^{\circ}$ were included in this study, divided into two groups of 30 each: $30-59^{\circ}$ and $60-99^{\circ}$ of curvature.

\section{Root canal instrumentation}

The root canals were then divided in four groups $(n=15)$ : Group 30-59M2 and Group 30-59TF, the root canals with moderate curvature, $30-59^{\circ}$, were instrumented by M2 and TF systems, respectively; and Group 60-99M2 and Group 60-99TF, the root canals with a severe curvature of $60-99^{\circ}$, were likewise instrumented by M2 and TF systems, respectively.

The sequence for groups instrumented with M2 was as follows: \#10/04, \#15/05, \#20/06 and \#25/06 were used to their full length in permanent rotation with a gentle inand-out motion. For the TF groups, a manual glide path up K-file \#20 (Dentsply/Maillefer) was used. Instrumentation was completed in a crown-down manner according to the manufacturer's instructions, using a gentle in-and-out motion. Instruments were withdrawn when resistance was felt and changed for the next instrument as follows: \#25/08, \#25/06, \#25/04 at WL and \#25/06 at WL. With both systems, a 4:1 reduction handpiece (WD$66 \mathrm{EM}$; W \& H, Buermoos, Austria) powered by a torque limited electric motor (Endo IT motor; VDW, Munich, Germany) was used according to the manufacturer's instructions. The root canals were flushed with $20 \mathrm{~mL}$ of a $2.5 \% \mathrm{NaOCl}$ solution using a plastic syringe with a closed-end needle (Hawe Max-I-probe; Kerr-Hawe, Bioggio, Switzerland) inserted as deep as possible into the root canal without binding. Each set of files was re- jected after five uses.

\section{Assessment of root canal preparation}

Postoperative radiographs were taken with the last file employed inside the root canals. The digital radiographs were downloaded in JPG format from the digital radiographic system and imported into Adobe Photoshop CS4. The images were then transferred to AutoCAD 2008 , to superimpose the central axis of files in the preand post-operative radiographs, so as to measure the distance between these two central axes at working length (Fig. 2).

The evaluated parameters were: straightening of root canal curvature, apical transportation at one (AT1) and two (AT2) millimetres of working length, loss of working length and working time, including time of irrigation and changes of files.

Statistical analysis

Mean and standard deviations were determined for each group. The Shapiro-Wilk test was used to assess the distribution of the data. Given that the apical transportation, loss of working length and working time results for each group did not follow a normal distribution, the MannWhitney $U$-test was used for pairwise comparisons. The data on straightening of root canal curvature were compared using the Student's $t$-test. The level of statistical significance was set at $p<0.05$. All statistical analyses were performed by means of SPSS 15.0 software (SPSS Inc., Chicago, IL, USA)

\section{Results}

Means and standard deviation values are shown in Table 1. The highest straightening of curvature $\left(13.69^{\circ}\right)$ occurred in the TF group with the root canals with 60-99 degrees of curvature, but gave no significant differences $(p=0.155)$ as opposed to the group of $30-59^{\circ}\left(8.40^{\circ}\right)$. No statistically significant differences in the apical transpor-
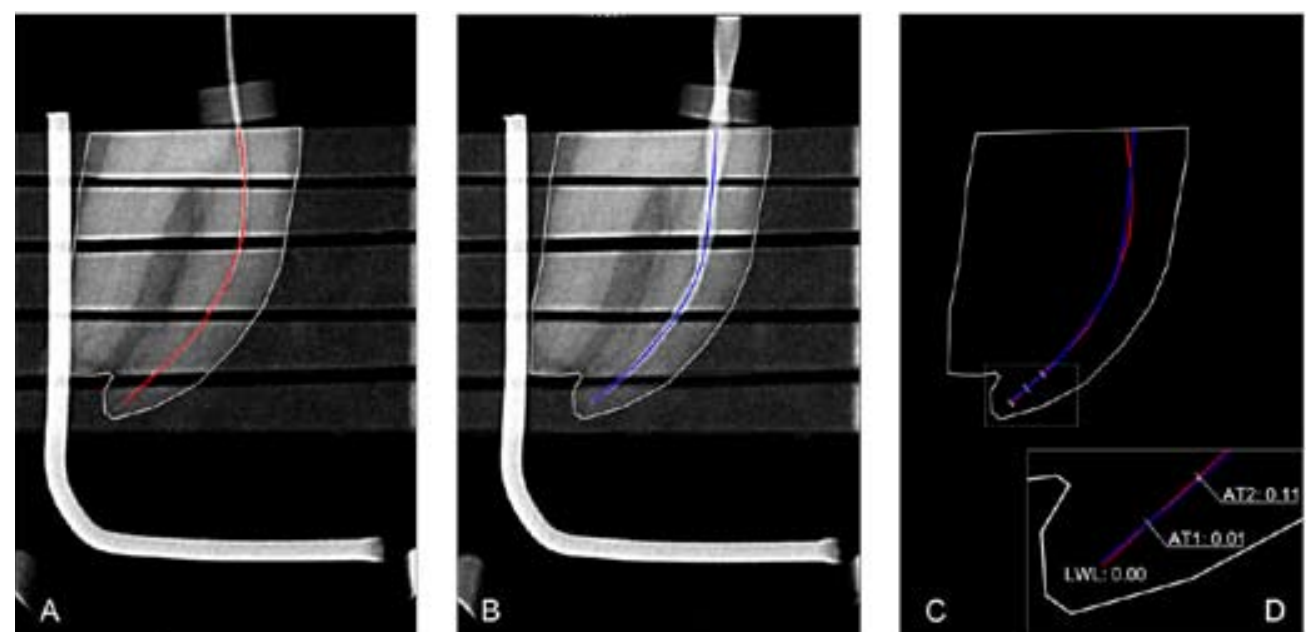

Fig. 2. Representative images of superimposed radiographic method. A. Central axis of pre-instrumentation; $B$. Central axis of post-instrumentation; C. Pre- and post-instrumented axes superimposed; D. Measurement of loss of working length (LWL), apical transportation at one millimeter of working length (AT1) and apical transportation at two millimetres of working length (AT2). 


\begin{tabular}{|c|c|c|c|c|c|c|}
\hline & \multicolumn{2}{|c|}{ Curvature $30-59^{\circ}$} & \multicolumn{2}{|c|}{ Curvature 60-99 } & \multicolumn{2}{|c|}{$\begin{array}{c}\text { Comparison } \\
30-59^{\circ} \text { vs } 60-99^{\circ}(p)\end{array}$} \\
\hline & M2 system & TF system & M2 system & TF system & M2 system & TF system \\
\hline $\begin{array}{l}\text { Straightening of } \\
\text { curvature (degree) }\end{array}$ & $9.40 \pm 6.854^{\mathrm{a}}$ & $8.40 \pm 7.219^{\mathrm{a}}$ & $7.92 \pm 7.488^{\mathrm{b}}$ & $13.69 \pm 11.672^{\mathrm{b}}$ & 0.591 & 0.155 \\
\hline AT 1 (millimeters) & $0.11 \pm 0.070^{\mathrm{a}}$ & $0.13 \pm 0.098^{\mathrm{a}}$ & $0.07 \pm 0.035^{\mathrm{b}}$ & $0.09 \pm 0.084^{\mathrm{b}}$ & 0.159 & 0.263 \\
\hline AT 2 (millimeters) & $0.14 \pm 0.126^{\mathrm{a}}$ & $0.11 \pm 0.086^{\mathrm{a}}$ & $0.09 \pm 0.067^{\mathrm{b}}$ & $0.08 \pm 0.052^{\mathrm{b}}$ & 0,368 & 0.380 \\
\hline $\begin{array}{l}\text { Loss of working length } \\
\text { (millimeters) }\end{array}$ & $0.25 \pm 0.322^{\mathrm{a}}$ & $0.37 \pm 0.489^{\mathrm{a}}$ & $0.28 \pm 0.333^{\mathrm{b}}$ & $0.43 \pm 0.435^{\mathrm{b}}$ & 0.924 & 0,641 \\
\hline Working time (seconds) & $339.47 \pm 67.619^{\mathrm{a}}$ & $377.60 \pm 122.695^{\mathrm{a}}$ & $436.31 \pm 136.732^{b}$ & $391.92 \pm 182.842^{\mathrm{b}}$ & 0.025 & 0.807 \\
\hline
\end{tabular}

M2: Mtwo. TF: Twisted Files.

AT 1: apical transportation at one millimeter to working length.

AT 2: apical transportation at two millimeter to working length.

Read horizontally, the values with the same letters did not show significant differences.

Table 1. Means and standard deviations of the variables at different curvature degrees $(\bar{x} \pm s)$.

tation at 1 and 2 millimetres to working length were recorded when comparing between either instrumentation systems or curvature degrees. Similarly, no significant differences were found when comparing the results of the loss of working length between systems or curvatures. Comparison of the results of working time between curvature degrees gave a statistically significant difference between the two M2 system groups ( $\mathrm{p}=0.025)$, although there was no significant difference between instrumentation systems in terms of degree of curvature.

\section{Discussion}

Maintenance of the original root canal shape is an important goal in root canal preparation, and different $\mathrm{NiTi}$ rotary instruments are used to obtain this objective. Several methods have been used to evaluate changes in root canals after instrumentation (18). Due to the high costs (economic and timewise) of computer tomography (19), the radiographic superimposition technique (7) and Bramante's technique (20) are widely used in endodontic research. So, radiographic digital imaging can be used to measure apical transportation and other parameters by comparing pre- and post-operative images in buccal or proximal views (21).

Schneider's method (22) has been used extensively in the quantification of root canal curvatures $(3,8,15)$. Unfortunately, this method ignores the radius of curvature, an important parameter in the evaluation of curved root canals. In our study, Pruett's method (17) was used to determine the angle and radius of curvature, so that the root canals of study could be equally distributed among the four study groups.

Newly designed NiTi instruments decrease the incidence of iatrogenic events and improve the safety in the preparation of the root canals. The pseudoelastic property of NiTi alloy is responsible for its tendency to recover the original form when working in curved root canals (23). In our study, the range of straightening of root canal curvature was between $7.9^{\circ}$ and $9.4^{\circ}$ in both the M2 groups, and between $8.4^{\circ}$ to $13.7^{\circ}$ in the two TF groups. Recently, a study using Mtwo (24) in root canals with moderate and severe curvature $\left(25-76^{\circ}\right)$ showed that straightening ranged from 4.4 to 10.6 degrees. However, when comparing the shaping ability of Mtwo with two different torque-limited automated devices in extracted human teeth, with angles of root canal curvature between 25 and 35 degrees, the straightening was of $1.2^{\circ}-2.2^{\circ}$ (25). Such results point to a major tendency towards straightening the root canal when the angle is increased. Iqbal et al. (18), using the radiographic superimposition method in mesial root canals of mandibular molar with varying degrees of root curvatures found a loss of working length between $0.15-0.30 \mathrm{~mm}$ using Profile and Protaper NiTi systems. Veltri et al. (26) showed a loss of working length of $0.55 \mathrm{~mm}$ with Mtwo and $0.58 \mathrm{~mm}$ with Endoflare-Hero Shaper in mandibular molar root canals with curvatures from 24 degrees to 69 degrees and more recently Martín-Micó et al. reported a loss of working length close to $1 \mathrm{~mm}$ in plastic blocks with double curvature using Mtwo system (27). In our study the loss of working length ranged from $0.25-0.28 \mathrm{~mm}$ with $\mathrm{M} 2$ and $0.37-0.43 \mathrm{~mm}$ with TF. In this sense, the helicoidal angle and variable pitch of M2 and TF systems favours the evacuation of detritus and avoids their compaction in the apical third, so the straightening of curved root canals observed with both NiTi system and the use of greater taper file, in the TF groups, might be responsible of loss of working length that has been shown in this research. The design (10), manufacturing characteristic (14) and instrumentation technique of NiTi systems seem to play a fundamental role in the shaping ability of curved root canals. It is know that apical transportation of more than $0.3 \mathrm{~mm}$ can have a negative impact on the seal of the obturation (28) and that apical transportation increases in 
curved root canals with an increase of file size (6). In this work the root canals were instrumented onto .25 tip, and the results of apical transportation for both systems were equal to or less than 0.15 millimetres (Table 1), similarly to previous studies using M2 $(8,24,26)$ and $\mathrm{TF}(15)$. Despite the major apical transportation found with M2 (in contrast with TF) in severe and moderate curvatures, no significant differences were found between the two systems. The minor values of apical transportation with TF system could be due to the crown-down instrumentation technique, which reduces the friction in the root canal when the file cuts dentin, as only a part of the file works within the root canal (24). Relatively minor friction means less incidence of apical transportation, since the files enter the root canal more freely (29).

The M2 system needed significantly more time in the instrumentation of root canals with severe curvature despite that the instrumentation was performed without glide path (24). The non-use of a manual glide path may difficult the instrumentation sequence, overcoat in pronounced curves of the root canals, requiring more time for their instrumentation. Moreover, the fact that the TF system works with 500rpm while the M2 system works with 280rpm (following manufacturers' recommendations) is a circumstance that no doubt contributed to the differences in working time experienced under the two systems. Yet no significant difference was found between the TF groups in moderate and severely curved root canals, which might be attributed to the manufacturing process of TF instruments (30), providing for fast instrumentation in difficult root canals.

Within the limitations of the present study, we may conclude that M2 and TF are both capable of rapidly preparing root canals with moderate and severe curvature, with minimal apical transportation and loss of the working length.

\section{References}

1. Peters OA. Current challenges and concepts in the preparation of root canal systems: a review. J Endod. 2004;30:559-67.

2. Greene KJ, Krell KV. Clinical factors associated with ledged canals in maxillary and mandibular molars. Oral Surg Oral Med Oral Pathol. 1990;70:490-7.

3. Schäfer E, Vlassis M. Comparative investigation of two rotary nickel-titanium instruments: ProTaper versus RaCe. Part 1. Shaping ability in simulated curved canals. Int Endod J. 2004;37:22938 .

4. Walia HM, Brantley WA, Gerstein H. An initial investigation of the bending and torsional properties of Nitinol root canal files. $J$ Endod. 1988;14:346-51.

5. Gambill JM, Alder M, del Rio CE. Comparison of nickel-titanium and stainless steel hand-file instrumentation using computed tomography. J Endod. 1996;22:369-75.

6. Setzer FC, Kwon TK, Karabucak B. Comparison of apical transportation between two rotary file systems and two hybrid rotary instrumentation sequences. J Endod. 2010;36:1226-9.

7. Iqbal MK, Maggiore F, Suh B, Edwards KR, Kang J, Kim S. Comparison of apical transportation in four Ni-Ti rotary instrumentation techniques. J Endod. 2003;29:587-91.

8. Schäfer E, Erler M, Dammaschke T. Comparative study on the shaping ability and cleaning efficiency of rotary Mtwo instruments: part 1-shaping ability in simulated curved canals. Int Endod J. 2006;39:196-202.

9. Schäfer E, Erler M, Dammaschke T. Comparative study on the shaping ability and cleaning efficiency of rotary Mtwo instruments: part 2-cleaning effectiveness and shaping ability in severely curved root canals of extracted teeth. Int Endod J. 2006;39:203-12.

10. Zhang EW, Cheung GS, Zheng YF. Influence of cross-sectional design and dimension on mechanical behavior of nickel-titanium instruments under torsion and bending: a numerical analysis. J Endod. 2010;36:1394-8.

11. Schäfer E, Oitzinger M. Cutting efficiency of five different types of rotary nickel-titanium instruments. J Endod. 2008;34:198-200.

12. Plotino G, Grande NM, Melo MC, Bahia MG, Testarelli L, Gambarini G. Cyclic fatigue of NiTi rotary instruments in a simulated apical abrupt curvature. Int Endod J. 2010;43:226-30.

13. Shahi S, Mokhtari H, Rahimi S, Shiezadeh V, Ashasi H, Abdolrahimi M, Foroughreyhani M. Electrochemical corrosion assessment of RaCe and Mtwo rotary nickle-titanium instruments after clinical use and sterilization. Med Oral Patol Oral Cir Bucal. 2012;17:e331-6.

14. Gambarini G, Grande NM, Plotino G, Somma F, Garala M, De Luca M, Testarelli L. Fatigue resistance of engine-driven rotary nickel-titanium instruments produced by new manufacturing methods. J Endod. 2008;34:1003-5.

15. Gergi R, Rjeily JA, Sader J, Naaman A. Comparison of canal transportation and centering ability of twisted files, Pathfile-ProTaper system, and stainless steel hand K-files by using computed tomography. J Endod. 2010;36:904-7.

16. Kuttler S, Garala M, Perez R, Dorn SO. The endodontic cube: a system designed for evaluation of root canal anatomy and canal preparation. J Endod. 2001;27:533-6.

17. Pruett JP, Clement DJ, Carnes DL Jr. Cyclic fatigue testing of nickel-titanium endodontic instruments. J Endod. 1997;23:77-85.

18. Iqbal MK, Firic S, Tulcan J, Karabucak B, Kim S. Comparison of apical transportation between ProFile and ProTaper NiTi rotary instruments. Int Endod J. 2004;37:359-64.

19. Peters OA, Laib A, Göhring TN, Barbakow F. Changes in root canal geometry after preparation assessed by high-resolution computed tomography. J Endod. 2001;27:1-6.

20. Bramante CM, Berbert A, Borges RP. A methodology for evaluation of root canal instrumentation. J Endod. 1987;13:243-5.

21. Aguiar CM, Câmara AC. Radiological evaluation of the morphological changes of root canals shaped with ProTaper for hand use and the ProTaper and RaCe rotary instruments. Aust Endod J. 2008;34:115-9.

22. Schneider SW. A comparison of canal preparation in straight and curved root canals. Oral Surg Oral Med Oral Pathol. 1971;32:271-5.

23. Thompson SA. An overview of nickel-titanium alloys used in dentistry. Int Endod J. 2000;33:297-310.

24. Uroz-Torres D, González-Rodríguez MP, Ferrer-Luque CM. Effectiveness of a manual glide path on the preparation of curved root canals by using Mtwo rotary instruments. J Endod. 2009;35:699702 .

25. Bürklein S, Schäfer E. The influence of various automated devices on the shaping ability of Mtwo rotary nickel-titanium instruments. Int Endod J. 2006;39:945-51.

26. Veltri M, Mollo A, Mantovani L, Pini P, Balleri P, Grandini S. A comparative study of Endoflare-Hero Shaper and Mtwo NiTi instruments in the preparation of curved root canals. Int Endod J. 2005;38:610-6.

27. Martín-Micó M, Forner-Navarro L, Almenar-García A. Modification of the working length after rotary instrumentation: a comparative study of four systems. Med Oral Patol Oral Cir Bucal. 2009; $14: 153-7$.

28. Wu MK, Fan B, Wesselink PR. Leakage along apical root fillings in curved root canals: part I-effects of apical transportation on seal of root fillings. J Endod. 2000;26:210-6. 
29. Roane JB, Sabala CL, Duncanson MG Jr. The "balanced force" concept for instrumentation of curved canals. J Endod. 1985;11:203-11.

30. Park SY, Cheung GS, Yum J, Hur B, Park JK, Kim HC. Dynamic torsional resistance of nickel-titanium rotary instruments. J Endod. 2010;36:1200-4. 